\title{
CHARACTERIZING CERAMICS AND THE INTERFACIAL ADHESION TO RESIN: I - THE RELATIONSHIP OF MICROSTRUCTURE, COMPOSITION, PROPERTIES AND FRACTOGRAPHY
}

\author{
CARACTERIZAÇÃO DE CERÂMICAS E ADESÃO À RESINA: I - RELAÇÃO ENTRE \\ MICROESTRUTURA, COMPOSIÇÃO, PROPRIEDADES E FRACTOGRAFIA
}

\author{
Alvaro DELLA BONA
}

University of Passo Fundo, Dental School, Passo Fundo, Brazil.

Corresponding address: Prof. Dr. Alvaro Della Bona - Dental School, University of Passo Fundo - Campus I - BR 285 - POBox 611 Passo Fundo, RS 99001-970 - Brazil - Phones: 55-54-581-0657 and 55-54-311-5142 - E-mail: dbona@upf.br

\begin{abstract}
I and anticipated unique tribological characteristics. A major goal of current ceramic research and development is to produce tough, strong ceramics that can provide reliable performance in dental applications. Quantifying microstructural parameters is important to develop structure/property relationships. Quantitative microstructural analysis provides an association among the constitution, physical properties, and structural characteristics of materials. Structural reliability of dental ceramics is a major factor in the clinical success of ceramic restorations. Complex stress distributions are present in most practical conditions and strength data alone cannot be directly extrapolated to predict structural performance.

Uniterms: Ceramics; Microstructure; Fracture strength; Fracture toughness; Fracture surface.
\end{abstract}

\begin{abstract}
RESUMO
apelo das cerâmicas como materiais odontológicos é baseado no seu peso leve, dureza alta, inércia química e características tribológicas únicas. Um dos maiores objetivos atuais das pesquisas com cerâmicas é a produção de materiais resistentes que possam oferecer uma utilização confiável para o uso odontológico. A quantificação dos parâmetros microestruturais é importante para o desenvolvimento da relação entre estrutura e propriedades. A análise quantitative da microestrutura fornece uma associação entre a composição, as propriedades físicas, e as características estruturais dos materiais. A confiabilidade estrutural das cerâmicas odontológicas é um fator importante para o sucesso clínico das restaurações cerâmicas. Distribuições complexas de estresse estão presentes na maioria das situações clínicas e, por isso, os valores isolados de resistência não podem ser diretamente extrapolados para prever a durabilidade estrutural dos materiais.

Uniterms: Cerâmica; Microestrutura; Resistência à fratura; Tenacidade de fratura; Superfície de fratura.
\end{abstract}

\section{INTRODUCTION}

This two-part review is design to demonstrate (1) the relationship of microstructure, composition, ceramics properties and the resulting characteristics of the fracture surfaces, and (2) the relationship between the ceramics characterization, the surface treatment and the bonding interface to resin, which is discussed in the second part of this review.

Microscopic examination is useful for the study and characterization of materials. Examination of microstructures is often related to material properties and the information is used to predict properties and improve the design of new materials ${ }^{17}$.

Structurally, all materials are either crystalline, partially crystalline, or amorphous. Most of crystalline ceramics, except for single crystals, are actually polycrystalline because they are made up of a large number of small crystals, or grains, separated from one another by grain boundaries. The atoms are bonded less regularly along a grain boundary, and consequently, there is an interfacial or grain boundary energy similar to the surface energy. Therefore, grain 
boundaries are more chemically reactive than the grains themselves and this concept has been used to enhance the observation of different material phases by lightly etch the ceramic surface before microscopy analysis ${ }^{6}$.

There are important relationships between chemical composition, atomic structure, fabrication process, microstructure, and properties of polycrystalline ceramics. The role of the fabrication process, for example, is to produce microstructures with desired chemical characteristics and properties. Each processing step has the potential for producing undesirable microstructural flaws in the ceramic body that can limit its properties and reliability. Thus, the microstructure, which refers to the nature, size, shape, quantity, and distribution of the structural elements or phases in the ceramics, has a profound effect on physical properties. In addition, recent ceramic research has concentrated on developing a fundamental understanding of ceramic damage/failure modes as influenced by microstructure ${ }^{17,64}$.

Fractography has been used to quantitatively relate the stress at failure, the nature of the stress state, and the amount of residual stress relative to the sizes of the initial crack and surrounding topography ${ }^{20,49}$. Quantitative fractographic analysis of brittle fracture surfaces shows that there are characteristic markings on the surfaces that are self-similar and scale invariant, implying that fractal analysis is a reasonable approach to analyzing these surfaces ${ }^{16,31,79}$.

The specific aims of this two-paper review are as follows: (1) to demonstrate the importance of characterizing the microstructure, composition, and basic properties of dental ceramics and the relationship with surface topography and the work of adhesion ( $\left.\mathrm{W}_{\mathrm{A}}\right)$; (2) to point the differences in calculating the flexural strength of monolithic and multilayered ceramic specimens; and (3) to comment on the use of Weibull modulus, fractal dimensional increment (D*), fracture toughness $\left(\mathrm{K}_{\mathrm{C}}\right)$ and microtensile bond strength test to predict the structural reliability of ceramics and its bond interface to resin.

\section{Characterization of Microstructure, Composition and Properties of Dental Ceramics}

There are several physical and mechanical properties that are used to characterize the behavior of ceramics, such as: elastic modulus, Poisson's ratio, hardness, density, fracture strength and toughness.

The elastic or Young's modulus (E) is a measure of the stiffness, or the material's resistance to elastic deformation. The greater the modulus, the stiffer the material, or the smaller the elastic strain that results from the application of a given stress. The modulus is an important design parameter used for computing elastic deflections. The best of all methods of measuring $\mathrm{E}$ is to measure the velocity of sound in the material.

Poisson's ratio (v) is the ratio of the lateral to axial strain. Theoretically, a typical $v$ value for isotropic materials is 0.25 , but the maximum may be as high as 0.50 . It is related to the shear modulus $(\mathrm{G})$ and elastic modulus $[\mathrm{E}=2 \mathrm{G}(1+v)]$.
Hardness $(\mathrm{H})$ is a measure of material's resistance to plastic deformation. In a hardness test a load is placed on an indenter that is driven into the surface of the specimen. The degree to which the indenter penetrates the sample is a measure of the material's ability to resist plastic deformation. Material's properties such as tensile strength, wear resistance due to friction, and fatigue resistance have been predicted from hardness data ${ }^{6}$.

The volume of crystalline materials and their volume changes with temperature are closely related to the crystal structures. The density $(\rho)$ is directly determined by the crystal structure, that is, the efficiency of atomic packing. The density, as usually measured $\left(\mathrm{g} / \mathrm{cm}^{3}\right)$, depends on the number of atoms per cubic centimeter and on the atomic weight of the constituents. The volume of a glass is largely determined by the nature of the vitreous network. The density is a minimum value for the pure network former and increases as modifier ions are added ${ }^{42}$.

The structure of each phase in dental ceramics depends greatly upon the firing conditions such as pre-heating temperature, heating rate, final firing temperature, hold-time at final temperature, atmosphere in firing oven, and the cooling rate. The coefficient of thermal expansion (CET), strength $(\sigma)$ values, chemical solubility, transparency, and appearance are some of the properties that show some dependency on the degree and manner to which the structure is fired. The test methods to measure ceramic properties are standardized by the ISO $6872^{35}$.

Some studies reported the chemical composition of certain dental ceramics using wavelength dispersive spectroscopy (WDS), electron dispersive spectroscopy (EDS), X-ray photoelectron spectroscopy (XPS), X-ray diffraction XRD, and Fourier-transform infrared reflection spectroscopy (FTIR) ${ }^{3,10,14,17,34,45,70}$. Others reported the composition of specific crystal phases, e.g. leucite ${ }^{17,20,23,46,63}$. Analyses of surface and bulk composition of commercially available feldspathic ceramics using XPS, WDS, and EDS have shown the presence of a silica-rich surface layer due to a reduction in $\mathrm{K}$ and Na relative to the bulk composition. However, the surface composition and chemical states of the ceramics were found to be virtually indistinguishable. This suggests that the compositional analysis protocol can use methods that collect the information up to $1 \mu \mathrm{m}$ from the specimen surface, such as WDS and EDS 17,20,34.

The microstructure of some dental ceramics has also been studied and related to physical properties 7,17,23,24. The high-expanding mineral, leucite $\left(\mathrm{K}_{2} \mathrm{O} \cdot \mathrm{Al}_{2} \mathrm{O}_{3} \cdot 4 \mathrm{SiO}_{2}\right)$, is often associated with microcracks that result from a thermal expansion mismatch between leucite and the surrounding glass matrix (Figure 1) ${ }^{14,17,22,47}$. This type of microcracking can be minimized by reducing the leucite particle size and by obtaining a homogeneous distribution of these particles throughout the ceramic (Figure 2) ${ }^{17,47}$. Previous research has also shown that the fracture energy first increases with increasing grain size because of increased cracking, then decreases because of more pre-existing microcracks ${ }^{17,80}$. These microcracks are rarely observed in high crystalline content ceramics and in glass-infiltrated or hot-pressed 
ceramics (Figure 3).

Quantitative and qualitative analyses of the microstructure are normally performed using scanning electron microscopy (SEM) in back scattered imaging (BSI) mode, followed by EDS or WDS based on Phi-Rho-Z (PRZ) correction. PRZ is a type of matrix correction scheme that uses a set of equations to correct for X-ray absorption, atomic number effect, and fluorescence from different elements in the sample.

To enhance the observation of microstructural features, e.g., grains and grains boundaries, the ceramic specimens are normally light etched. As ceramics are usually not conductive materials, the specimens should be mounted on aluminum stubs using carbon coating paste or tape for better

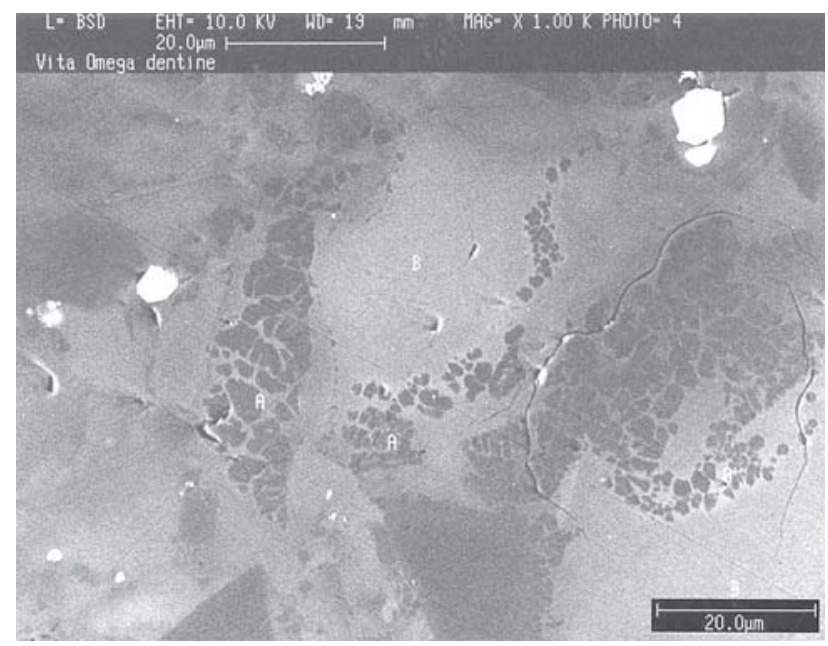

FIGURE 1- Photomicrograph of Vita Omega dentine ceramic (Vita Zahnfabrik, Bad Sackingen, Germany), a leucite based feldspathic ceramic. BSI of the microstructure showing (A) clusters of leucite in the glass matrix (B). Cracks can be observed around the leucite clusters; bright particles are zirconia $\left(\mathrm{ZrO}_{2}\right)^{17}$

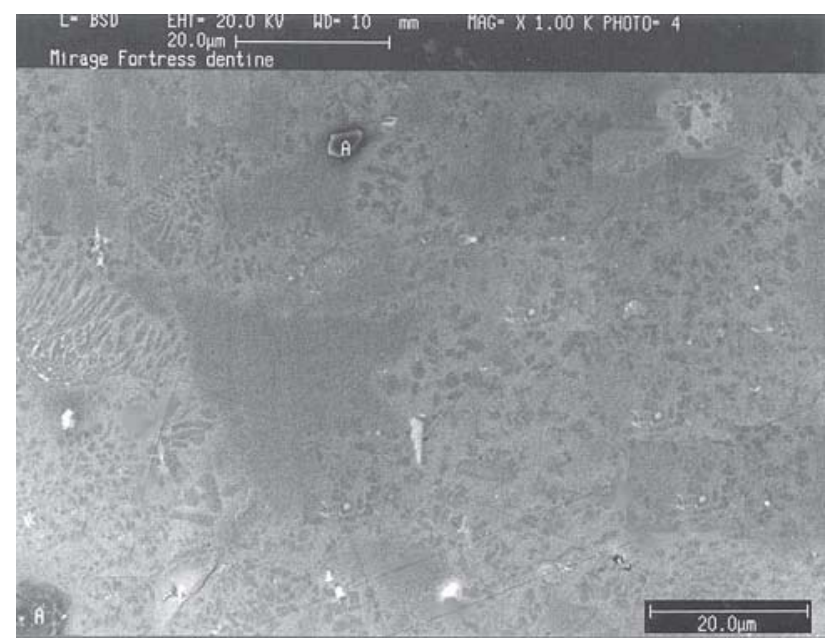

FIGURE 2- Photomicrograph of Fortress (Mirage Dental Systems, Kansas City, KS, USA), a leucite reinforced ceramic. $B S I$ of the microstructure; dark particles $(A)$ are alumina $\left(\mathrm{Al}_{2} \mathrm{O}_{3}\right)$. Note that leucite crystals are dispersed in the glass matrix and no cracks are found ${ }^{17}$ conductivity and sputter-coated with gold-palladium or carbon. Gold coating is recommended for surface topography analyses using the SEI mode and carbon coating should be used on specimens in which the main purpose is compositional analysis using BSI mode and EDS or WDS. The reason for this distinction is that gold-palladium coats produce element peaks that interfere in the compositional analysis.

Crystal size and volume fraction of crystal phases $\left(\mathrm{V}_{\mathrm{v}}\right)$ are important parameters in the materials characterization and can be measured using stereology principles. Stereology describes the relationship between measurements made on the two-dimensional plane of polished surfaces and the three-dimensional microstructural features to be sampled. Some studies have use stereology to measure the $\mathrm{V}_{\mathrm{V}}$ of dental ceramics and related it to their properties ${ }^{17,20,33}$.

The microstructural properties, such as $\mathrm{V}_{\mathrm{v}}$ and crystal size, are also important for the interpretation of fracture processes. Previous research has shown that the grain size and the crystal structure are correlated with the crack phenomena regardless of processing or composition ${ }^{80}$. When the grain size of the material becomes large with respect to flaw size, the crack does not encompass enough grains for the full polycrystalline toughness to apply. This results in a reduction in both fracture toughness and fracture strength. Yet, the dominant damage mode in any given material is dictated by the microstructure: (1) fine microstructures with minimal internal weakness tend to exhibit macroscopic cracks; and (2) coarse microstructures with enhanced internal weakness tend to exhibit quasiplastic zones. Both cracks and quasi-plasticity can lead to degradation of properties, and ultimately compromise the useful lifetimes of restorative structures, in different ways. The two modes may be interactive: the quasi-plasticity can enhance or inhibit fracture by redistributing tensile stresses $44,61,62$.

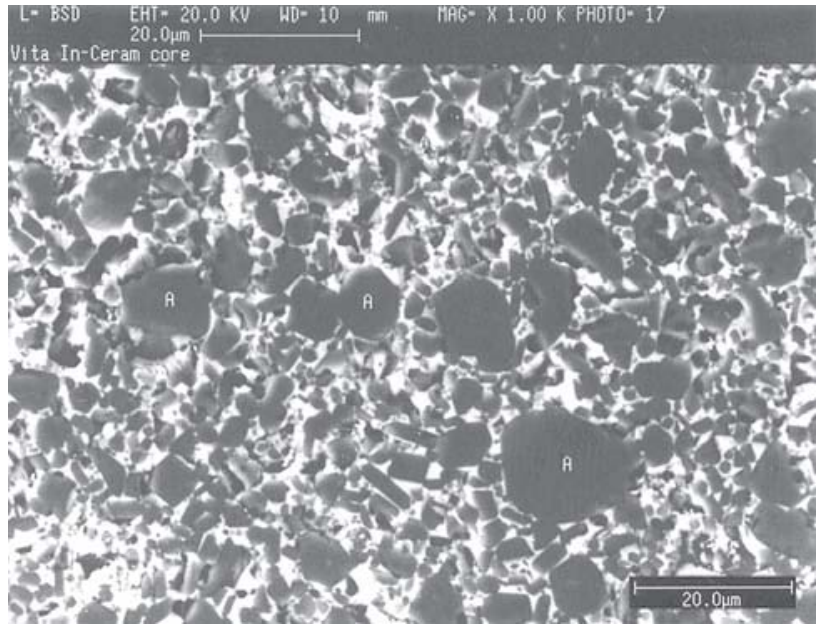

FIGURE 3- Photomicrograph of In-Ceram Alumina core ceramic (Vita Zahnfabrik, Bad Sackingen, Germany), a glass-infiltrated alumina based ceramic. BSI of the microstructure showing $(A)$ alumina $\left(\mathrm{Al}_{2} \mathrm{O}_{3}\right)$ particles (dark) in a lanthanum oxide base glass matrix (white) 
The effect of crystallization as a toughening mechanism for glass ceramics has also been studied ${ }^{20,27}$. It is known that a morphology that makes crack propagation more difficult, requiring more energy, increases toughness. Combination of toughening techniques can be microstructurally designed to optimize the toughness and strength of glass ceramics ${ }^{52}$.

Microstructure and composition are also controlling factors in the development of micromechanical retention produced by ceramic surface primers, such as acids, airborne-particle abrasion methods and electrodeposition technology and, therefore, affecting the bonding mechanisms to resin ${ }^{13-15,17,20}$. This subject will be thoroughly discussed in the second part of this two-paper review.

Therefore, quantitative and qualitative microstructural analyses provide an association among the constitution, physical properties, and structural characteristics of materials. In addition, the microstructure characterization is necessary to calculate relevant mechanical properties and to support further arguments on fracture and bonding phenomena. It is difficult to discuss materials behavior without proper material characterization, which should be the first step of any research proposal involving materials.

\section{Flexural Strength and Structural Reliability of Single- and Multilayer Ceramic Structures}

Mechanical failure occurs when the applied stress becomes greater than the strength of the material. The strength of a material is dependent on the size of the initiating crack present in a particular sample or component ${ }^{59}$. The large number of pre-existing ceramic cracks, coupled with a low fracture toughness, limit the strength of ceramics and cause a large variability in strength and time-dependency. Variability in strength is a consequence of the distribution in crack sizes, and the time dependency of strength results from the slow growth of these flaws to dimensions critical for catastrophic failure ${ }^{69}$.

Failure predictions for ceramics depend on the experimental parameters that measure the strength distribution and time dependency of strength. These parameters can be determined by measuring strength as a function of stressing rate in a test environment that simulates the service environment (Figure 4). Thus, well designed experiments coupled with a reliability analysis can optimize rational design decisions that ensure the successful use of ceramics in demanding structural applications ${ }^{19,68}$.

Flexural strength is generally considered as a meaningful mechanical property for brittle materials that are much weaker in tension than in compression. However, it is necessary to control the flaw distribution to validate this approach. Although the "strength" is used as a measure of reliability, toughness is a more meaningful property. Biaxial flexural, three- and four-point bending are the most popular test methods to assess the strength distribution found in components $\mathrm{s}^{35}$. The four-point flexure test has been used for strength evaluation of single-component brittle materials $s^{4,19,28}$ and bilayered structures such as glass veneer on core ceramic specimens ${ }^{19,74}$ and metal-ceramic structures $^{11,12}$.

The failure strength of a brittle material is statistically distributed as a function of the homogeneity of the material. One commonly used statistic for the description of this distribution parameter is the Weibull distribution. The Weibull modulus (m) is a measure of the distribution of critical flaws. Higher values of “m” correspond to a higher level of structural integrity of the material. Most ceramics are reported to have " $m$ " values in the range of 5 to 15 , whereas metals, which produce ductile failures, have " $m$ " values in the range of 30 to $100{ }^{37}$. This analytical method based on statistical concepts is easily applied when a reasonable number of samples are examined, and it enables fracture probability to be calculated as a function of applied stress ${ }^{19,50}$. Yet, Weibull analysis has some limitations that challenge its ability to predict failure of components having complex geometries, especially when they are subjected to a multi-axial stress state. This may play an important role when dental restorations are analyzed ${ }^{4}$. Therefore, the failure probability of monolithic and laminated ceramic structures can be calculated from the results of a flexural test ${ }^{19}$.

Surface cracks can be induced by machining or grinding. Usually, failure of the ceramic originates from the most severe flaw. The size and spatial distribution of flaws justify the necessity of a statistical approach to failure analysis ${ }^{78}$. Thus, the reliability of ceramics under flexural loading can be based on Weibull analysis.

Evaluation of the damage modes in bilayer ceramic structures using an Hertzian contact test has shown that the substrate has a profound influence on the evolution damage from initiation to ultimate failure in the bilayer systems ${ }^{38}$. Nevertheless, the crack initiation tends to occur at the top surface in systems having a strong bonded interface and a small elastic-plastic mismatch (glass/glassceramic); whereas in systems with a large mismatch, crack initiation tends to occur at the internal interface ${ }^{81}$. Yet, the

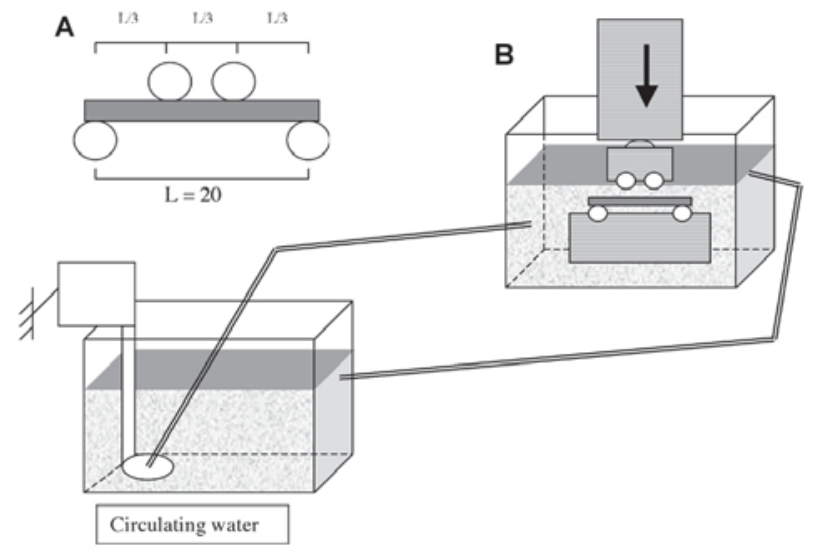

FIGURE 4- (A) Schematic representation of the four-point flexure test arrangement. The outer span length (L) is 20 $\mathrm{mm}$, and the inner span is $L / 3$. (B) Four-point flexural loading arrangement in $37^{\circ} \mathrm{C}$ distilled water (top right) provided by a circulating water bath (bottom left). This test method simulates the service environment. Adapted from Della Bona, et al. ${ }^{19}, 2003$ 
core/veneer thickness ratio $\left(\mathrm{t}_{\mathrm{C}} / \mathrm{t}_{\mathrm{v}}\right)$ appears to be the dominant factor that controls the failure initiation site in bilayer ceramic structures ${ }^{74,77}$. The crack initiation site shifts from veneer to core as the $t_{C} / t_{v}$ ratio increases, but the increase in the elastic modulus of the supporting substrate did not affect the crack initiation site ${ }^{77}$. Therefore, the load to fracture initiation is primarily influenced by the thickness of the restoration and, to a lesser extent, the $\mathrm{E}$ of the supporting substrate.

Investigations of clinically failed all-ceramic restorations have shown that the fracture origin is typically located at the internal (tensile) surface of the crowns ${ }^{39,40,75}$. These results suggest that the ceramic core surface should be placed as the tensile side for flexural testing of multi-layer structures ${ }^{19}$.

Mean flexural strength values also vary according to the test method and test environment. Same ceramic material can show up to $30 \%$ higher values if tested in three-point bending at room atmosphere than in four-point bending under water ${ }^{19,33}$.

Fracture surface analysis (fractography) is wellestablished as a means of failure analysis in the field of glasses and ceramics. It has been recognized as a powerful analytical tool in dentistry ${ }^{20,39,75}$. The application of fractography is based on the principle that the entire history of the fracture process is encoded on the fracture surface of brittle materials ${ }^{26,58}$.

Fracture in glass occurs when preexisting cracks propagate under excessive tensile stresses. These cracks can be induced by mechanical means (e.g., grinding or polishing), by processing, or by intrinsic defects (e.g., imperfections in the structure). Most evidence shows that crack propagation is determined by varying levels of stress intensity or energy and, because of these relationships, much information is contained within the fracture surface ${ }^{57}$. Fractography principles have been used for qualitative analysis of fracture dental restorations confirming the presence of characteristic markings of the fracture process (Figures 5 and 6) ${ }^{19,20}$. Note that these markings are more evident on the fracture surface of amorphous glasses (Figure 5) than on crystalline ceramics (Figure 6). As mentioned, fractography principles can be applied to analyze any fractured ceramic surface, however, the more complex the microstructure the more difficult to identify the characteristic fracture markings (Figures 5 and 6) and expert knowledge is mandatory.

Ceramic specimens tested in bending are very sensitive to edge or surface machining damage. Fractographic analysis has been shown that most failures start from either a surface (Figure 5) or a corner flaw (Figure 6) located along the tensile surface of the specimens ${ }^{19,20,68,74}$. These observations may suggest rounding specimen edges as a revision of the specimen preparation standard ISO $6872^{35}$, as proposed by Della Bona, et al. ${ }^{20}, 2004$.

In cases where the Weibull moduli are similar among experimental structures, a crack difference cannot explain the strength differences. Thus, the differences in strength can be explained by the differences in toughness that, in turn, are related to the way the materials are processed. For instance, if the mean flexural strength and Weibull modulus of a core monolithic ceramic are similar to those of the same core ceramic veneered by a glass (bylayered specimen) and the fracture analysis also shows similar results for these two structures, it can be said that the structural reliability of the veneered core ceramic structure is controlled primarily by that of the core ceramic. Yet, the investigator has to determine the critical core/veneer thickness ratio $\left(\mathrm{t}_{\mathrm{C}} / \mathrm{t}_{\mathrm{v}}\right)$ below which strength and structural reliability become significantly reduced. This information will improve our ability to design ceramic-based prostheses with a sufficiently high margin of safety ${ }^{19,20}$.

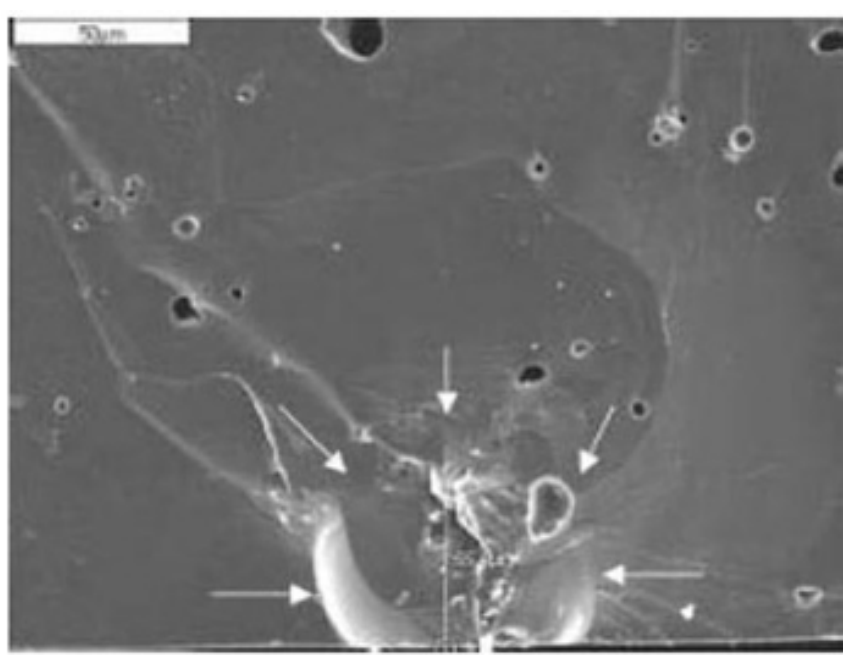

FIGURE 5- SEM micrograph of ceramic fracture surface showing a critical flaw (crack) outlined by white arrows. Fracture surface of a amorphous glass (IPS Empress2 body, Ivoclar AG, Schaan, Liechtenstein); note the tailed fracture markings (top right) pointing toward the crack origin; measured line represents the semiminor axis, a = $55 \mu \mathrm{m}$ (500x). From Della Bona, et al. ${ }^{20}, 2004$.

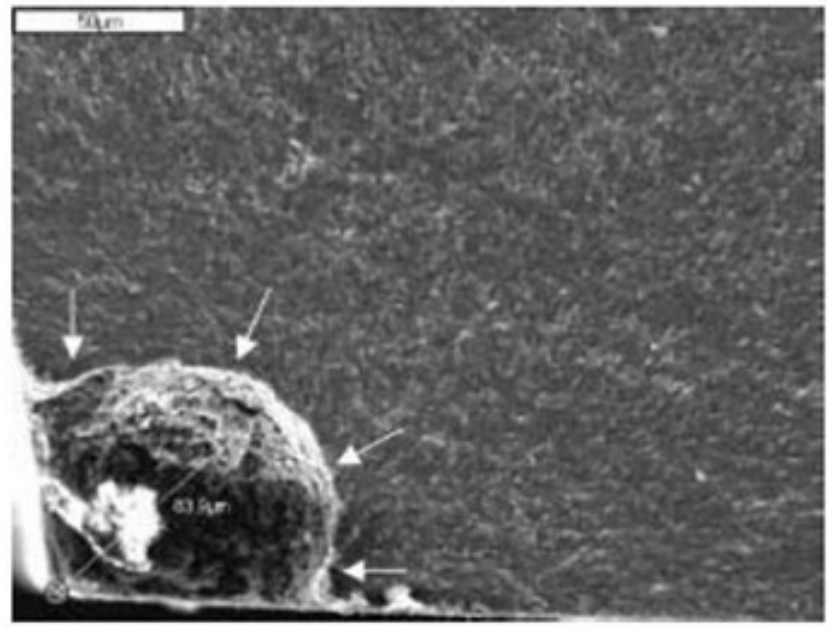

FIGURE 6- SEM micrograph of ceramic fracture surface showing a critical flaw (crack) located at the corner of the specimen (outlined by white arrows). Fracture surface of a leucite-based ceramic (IPS Empress, Ivoclar AG, Schaan, Liechtenstein); line from flaw corner, $c=84 \mu \mathrm{m}$ (500x). From Della Bona, et al. $.^{20}, 2004$. 


\section{Ceramic Fracture Toughness Determined by Fractography and Fractal Analyses}

Brittle fracture has been shown to be a complex process 26,29,79. The fracture process creates at least two new surfaces with distinct topography and texture that can be characterized using principles of fractography.

Most fracture surface observations yield substantial information about the fracture process and enable the calculation of the fracture toughness of the material. In addition, the roughness of the fracture surface gives qualitative information on the extent of crack deflection ${ }^{25,67}$, or other toughening mechanisms ${ }^{32}$.

It is difficult to directly measure the flaw-initiating site, especially in very high-strength, fine-grained glass ceramics, and in cases where failure is caused by poor machining practices. However, where the flaw itself cannot be measured, the region from which the failure occurred can be determined by observing the patterns on the fracture surface ${ }^{66}$. This is the case of the majority of multi-layer structures.

Quantitative fractographic analysis applies the principles of fracture mechanics to the topography observed on the fracture surface of brittle materials. There is specific, quantitative information to be obtained from the fracture surface including: (1) the identification of the size and location of the fracture initiating crack or defect, (2) the stress state at failure, (3) the existence, or not, of stress corrosion, (4) a knowledge of local processing anomalies that affect the fracture process, and (5) the calculation of the fracture toughness ${ }^{20,58}$.

Fracture toughness values are used extensively to characterize the fracture resistance of brittle materials $2,8,20,41,72,73$. The fracture toughness of brittle ceramics is usually controlled by the fracture in Mode I (opening mode, tensile load). Irwin (1957) ${ }^{36}$ defined failure at the point when the Mode I stress intensity $\left(\mathrm{K}_{\mathrm{I}}\right)$ reaches a critical value $\left(\mathrm{K}_{\mathrm{I}} \geq\right.$ $\left.\mathrm{K}_{\mathrm{IC}}\right)$. The critical stress intensity factor $\left(\mathrm{K}_{\mathrm{IC}}\right)$ is in many cases a material constant and is one measure of the toughness of the material, i.e. the resistance to crack propagation. Therefore, the fracture toughness or critical stress intensity factor $\left(\mathrm{K}_{\mathrm{IC}}\right)$ can often be determined using the Griffith-Irwin equation:

$$
\mathrm{K}_{\mathrm{IC}}=\mathrm{Y} \sigma_{\mathrm{f}} \mathrm{C}^{1 / 2}
$$

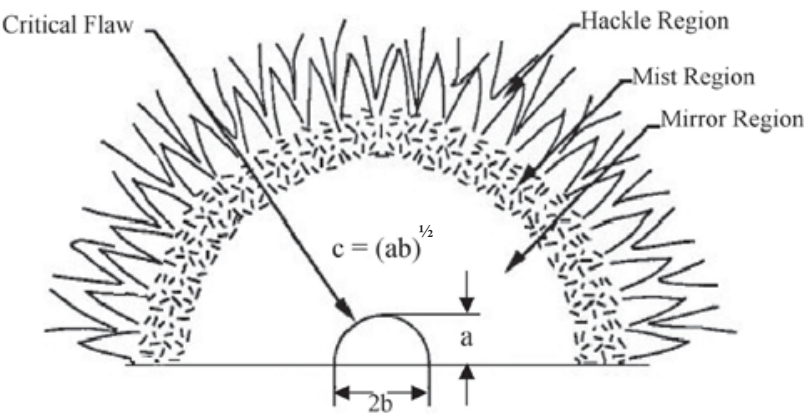

FIGURE 7- Diagram of the typical fracture surface features occurring in brittle materials. The regions are not drawn to scale $^{20}$ where $\mathrm{Y}$ is a geometrical factor that accounts for the location and geometry of the crack and loading ${ }^{20,65}, \sigma_{\mathrm{f}}$ is the stress at fracture, and $\mathrm{c}$ is the radius of an equivalent semicircular crack for a semi-elliptical crack of semiminor axis "a" and semimajor axis “b” (Figure 7) 20,51,59.

Therefore, the fractography approach to determine fracture toughness involves the identification and measurement of the initial (starting) defect or critical crack (c) using fractographic principles (Figure 7). In case of corner cracks (Figure 6), the critical size (c) is calculated using the same equation as for the equivalent semi-circular surface crack $\left[c=(a b)^{1 / 2}\right]$ (Figure 7) $)^{20}$. However, "a” is the length of one side of the corner crack and " $b$ " is the length of the other side of the corner crack. So, in this case, (c) corresponds to the distance from the crack corner to the critical flawmirror region limit, which corresponds to $84 \mu \mathrm{m}$ in Figure 6. For internal flaws (Figure 8), "c" is also calculated by [c = $\left.(a b)^{1 / 2}\right]$. However, "a" is half of the crack major axis and "b" is half of the crack minor axis.

Under certain service and/or environmental conditions, stable crack extension or slow crack growth can occur at stress intensities that are less than the critical value, $\mathrm{K}_{\mathrm{IC}}$. Under such conditions, $\mathrm{K}_{\mathrm{I}}$ becomes dependent on the crack growth rate (crack velocity, $\mathrm{V}$ ) and, hence, the characteristics of the system. The calculation of $\mathrm{K}_{\mathrm{IC}}$ in environmental conditions that promote slow crack growth can lead to erroneous values of $\mathrm{K}_{\mathrm{IC}}$ because of an incorrect assumption of (initial versus final) crack size. Nevertheless, the actual value of $\mathrm{K}_{\mathrm{IC}}$ should not change due to loading rate or test geometry. If the environment degrades the entire material, then the degraded material is, essentially, a different material. If the environment degrades the local crack, then the crack usually grows and the component is weaker, i.e., lower strength, but also with a larger final crack size, so the toughness of the unaffected region is still the same.

Quantitative fractographic analysis of brittle fracture surfaces shows that there are characteristic markings on the surfaces that are self-similar and scale invariant, implying that fractal analysis is a reasonable approach to analyzing

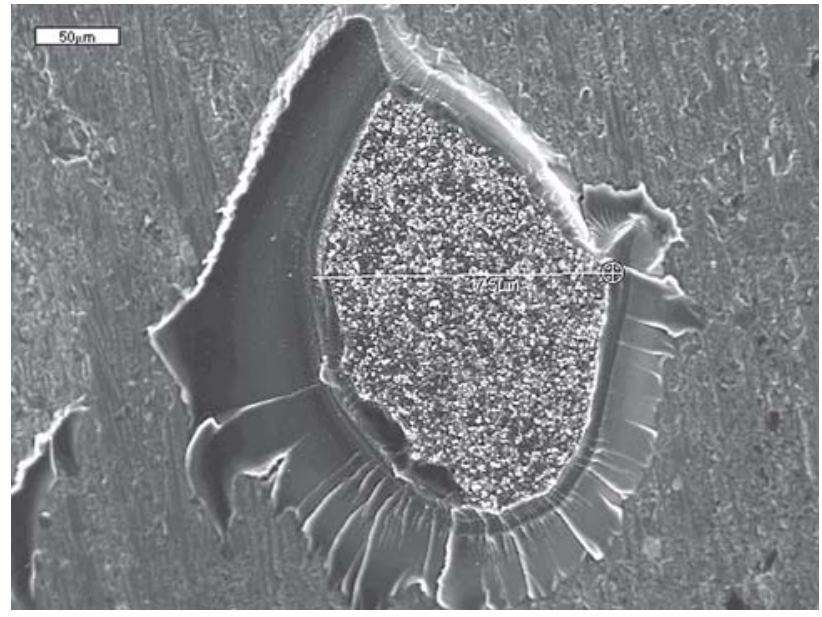

FIGURE 8- SEM micrograph of a fractured surface with an internal flaw as the crack origin (c); the measurement of the flaw minor axis is $2 b=175 \mu \mathrm{m}(\times 250)$. From Della Bona, et al. ${ }^{18}, 2003$ 
these surfaces ${ }^{16,31,79}$. The fracture surfaces of both monolithic and granular materials have been shown to have fractal characteristics ${ }^{54,76}$. The study of fracture surfaces using fractal geometry has led to the observation that tougher materials tend to form more complex, irregular fracture surfaces. In many cases, fractal geometry allows for the complexity of the surface features to be quantified by a single value, the fractal dimension ${ }^{49,54}$.

Fractal geometry is a non-Euclidean geometry that can quantitatively define irregular shapes and surfaces. Fractals are geometrical objects that are self-similar (or self-affine) and scale invariant and are characterized by non-integer dimensions. A scale invariant object is one in which the geometric surface will be statistically the same at any magnification scale ${ }^{5,16,31}$.

The use of fractal dimension, D, measurements to characterize rough surfaces, e.g. fracture surfaces, has become popular since Mandelbrot ${ }^{48}$ (1982) re-introduced the concept of fractal geometry. Several authors have used fractal geometry to quantitatively describe irregular fracture surfaces $1,9,16,31,49,54,56$. The larger the value of $\mathrm{D}$, the more tortuous the surface. Thus, a fracture surface may have a fractal dimension of 2.3 where 2 is the topological dimension and 0.3 is the fractal dimensional increment, $\mathrm{D}^{*}$.

Fractography also has been used to relate the flaw/mirror size ratio and the fracture toughness, which, in turn, is related to the elastic modulus. The combination of these relationships show that the $\mathrm{D}^{*}$ is directly related to the flaw/mirror size ratio. This implies that there is a linear scaling law between the energy of crack initiation and the energy of microbranching at fracture and this relationship is reflected in the features on the fracture surface ${ }^{16,31,55,60}$.

It has been shown that $\mathrm{D}^{*}$ is correlated to $\mathrm{K}_{\mathrm{IC}}$ for many brittle materials using the equation ${ }^{53}$ :

$$
\mathrm{K}_{\mathrm{IC}}=\mathrm{E} \mathrm{a}_{0}{ }^{1 / 2} \mathrm{D} * 1 / 2
$$

where $\mathrm{E}$ is the elastic modulus, and $\mathrm{a}_{0}$ is the characteristic fracture length on the atomic scale. The $a_{0}$ value is the slope of a graph of fracture energy $(\gamma)$ versus ED* $\left(a_{0}=2 \gamma / E^{*}\right)^{54}$. The $\mathrm{a}_{0}$ can be assumed to be $20-80 \AA$ for glass ceramic materials and $10-20 \AA$ for feldspathic ceramics ${ }^{16,31,53,79}$.

Therefore, the fractal approach for fracture toughness determination uses equation 2 and involves the calculation of the fractal dimensional increment (D*), which can be obtained using the slit-island analysis (SIA) along with the Richardson technique ${ }^{9,16,31,49,56,71}$. Thus, there is a positive correlation between $\mathrm{D}^{*}$ and $\mathrm{K}_{\mathrm{IC}}$ values. Although fractal analysis can be useful in failure analysis as one of many tools, it is not recommended to use fractal analysis alone as a standard technique for measuring toughness. However, the measurement of $\mathrm{D}^{*}$ on fracture surfaces of failed crowns or bridges can be potentially used to determine the difference between poor processing and over-load intra-oral failures.

\section{CONCLUSIONS}

This review demonstrated that quantitative microstructural analysis can provide an association among the constitution, physical properties, and structural characteristics of materials ${ }^{17}$. It also became evident that structural reliability of dental ceramics is a major factor in the clinical success of ceramic restorations. In addition, it has been shown that complex stress distributions are present in most practical conditions and strength data alone cannot be directly extrapolated to predict structural performance ${ }^{19,20,41}$.

Therefore, for the strength test to accurately reflect the variability and time-dependency of a ceramic component in service, the test environment must be similar to the service environment, and the strength-controlling flaw population must be the same as that responsible for failure in service. These factors should be the basis for the selection of a research protocol. As the distribution of strength is a measure of the distribution of the effective flaw sizes leading to failure, fractography principles should be applied for the quantitative and qualitative analyses of fractured surfaces, improving the understanding of the fracture phenomenon, which is, at the end, the most common failure cause of ceramic restorations.

\section{ACKNOWLEDGEMENTS}

This review is based on the knowledge gathered during the graduate course in Restorative Dentistry at the University of Texas Health Science Center at San Antonio, U.S.A., supervised by Dr. James B. Summitt, followed by the MMedSci program in Restorative Dentistry at the University of Sheffield, UK, supervised by Dr Richard van Noort, and, mainly, during the PhD program in Materials Science and Engineering at the University of Florida, USA, supervised by Dr Kenneth J. Anusavice and Dr John J. Mecholsky Jr. I also thank the continuing support of CNPqBrazil, grant 300659/03-2, for my research work at the University of Passo Fundo.

\section{REFERENCES}

1- Alexander DJ. Quantitative Analysis of Fracture Surfaces Using Fractals. In: Quantitative Methods in Fractography. Philadelphia: ASTM STP 1085; 1990. p. 39-51.

2- Anstis GR, Chantikul P, Lawn BR, Marshall DB. A critical evaluation of indentation techniques for measuring fracture toughness: I, direct crack measurements. J Am Cer Soc 1981;64:533-8.

3- Anusavice KJ. Degradability of dental ceramics. Adv Dent Res 1992; 6:82-9.

4- Ban S, Anusavice KJ. Influence of test method on failure stress of brittle dental materials. J Dent Res 1990; 69:1791-9.

5- Bouchaud JP, Bouchaud E, Lapasset G, Planes J. Phys Rev Ltrs 1993; 71:2240. 
6- Callister WD. Materials Science and Engineering: an Introduction. 5th ed. New York: John Wiley \& Sons, Inc.; 2000.

7- Cattell MJ, Clarke RL, Lynch EJ. The transverse strength, reliability and microstructural features of four dental ceramics - part 1. J Dent 1997;25:399-407.

8- Chantikul P, Anstis GR, Lawn BR, Marshall DB. A critical evaluation of indentation techniques for measuring fracture toughness: II, strength method. J Am Cer Soc 1981;64:539-43.

9- Chen Z, Mecholsky Jr. JJ, Joseph T, Beatty CL. The fractal geometry of $\mathrm{Si}_{3} \mathrm{~N}_{4}$ wear and fracture surfaces. J Mater Sci 1997;32: 6317-23.

10- Claus H. The structure and microstructure of dental porcelain in relationship to the firing conditions. Int J Prosthodont 1989; 2:37684

11- Coffey JP, Anusavice KJ, DeHoff PH, Lee RB, Hojjatie B. Influence of contraction mismatch and cooling rate on flexural failure of PFM systems. J Dent Res 1988;67:61-5.

12- DeHoff PH, Anusavice KJ, Hathcock PW. An evaluation of the four-point flexural test for metal-ceramic bond strength. J Dent Res 1982;61:1066-9.

13- Della Bona A. Cerâmicas: desenvolvimento e tecnologia. RFO UPF 1996;1:13-23.

14- Della Bona A, van Noort R. Ceramic surface preparations for resin bonding: a SEM study. Am J Dent 1998;11:276-80.

15- Della Bona A, Anusavice KJ, Shen C. Microtensile strength of composite bonded to hot-pressed ceramics. J Adhesive Dent 2000; 2:305-13.

16- Della Bona A, Hill TJ, Mecholsky Jr. JJ. The effect of contour angle on fractal dimension measurements for brittle materials. J Mater Sci $2001 ; 36: 2645-50$

17- Della Bona A, Anusavice KJ. Microstructure, composition, and etching topography of dental ceramics. Int J Prosthodont 2002;15:15967

18- Della Bona A, Anusavice KJ, Mecholsky Jr. JJ. Failure analysis of resin composite bonded to ceramic. Dent Mater 2003; 19:693-9.

19- Della Bona A, Anusavice KJ, DeHoff PH. Weibull analysis and flexural strength of hot-pressed core and veneered ceramic structures. Dent Mater 2003; 19:662-9.

20- Della Bona A, Anusavice KJ, Mecholsky Jr. JJ. Fracture behavior of lithia disilicate- and leucite-based ceramics. Dent Mater 2004;20:95662

21- Della Bona A, Shen C, Anusavice KJ. Work of adhesion of resin on treated lithia disilicate-based ceramic. Dent Mater 2004;20:338-44.

22- Della Bona A. Restaurações em cerâmica pura (metal-free) e mecanismos de adesão. In: Bottino MA. Livro do Ano da Clínica Odontológica Brasileira. São Paulo: Artes Médicas; 2004. p. 61-86.

23- Denry IL, Mackert Jr. JR, Holloway JA, Rosenstiel SF. Effect of cubic leucite stabilization on the flexural strength of feldspathic dental porcelain. J Dent Res 1996;75:1928-35.

24- Denry IL, Holloway JA, Rosenstiel SF. Effect of ion exchange on the microstructure, strength, and thermal expansion behavior of leucitereiforced porcelain. J Dent Res 1998;77:583-8.

25- Faber KT, Evans AG. Crack deflection processes - 1. Theory. Acta Metall 1983;31:565-76.
26- Fréchette VD. Failure analysis of brittle materials. Westerville, $\mathrm{OH}$ : American Ceramic Society; 1990.

27- Freiman SW, Hench LL. Effect of crystallization on the mechanical properties of $\mathrm{Li}_{2} \mathrm{O}-\mathrm{SiO}_{2}$ glass-ceramics. J Am Cer Soc 1972;55:86-90.

28- Giordano RA, Pelleiter L, Campbell S, Pober R. Flexural strength of an infused ceramic, glass ceramic, and feldspathic porcelain. J Prosthet Dent 1995;73:411-8.

29- Griffith AA. The phenomena of rupture and flow in solids. Philos Trans R Soc (London) 1920; 221:163-98.

30- Hertzberg RW. Deformation and fracture mechanics of engineering materials. $4^{\mathrm{a}}$ ed. New York: J. Wiley \& Sons; 1996.

31- Hill TJ, Della Bona A, Mecholsky Jr. JJ. Establishing a protocol for measurements of fractal dimension in brittle materials. J Mater Sci 2001;36:2651-7

32- Hill TJ, Mecholsky Jr. JJ, Anusavice KJ. Fractal analysis of toughening behavior in $3 \mathrm{BaO} \cdot 5 \mathrm{SiO}_{2}$ glass-ceramics. J Am Cer Soc 2000; $83 \cdot 545-52$

33- Höland W, Schweiger M, Frank M, Rheinberger V. A comparison of the microstructure and properties of the IPS Empress 2 and the IPS Empress glass-ceramics. J Biomed Mater Res 2000; 53:297-303.

34- Hooshmand T, Daw R, van Noort R, Short RD. XPS analysis of the surface of leucite-reinforced feldspathic ceramics. Dent Mater 2001;17:1-6.

35- International Organization for Standardization. ISO 6872: Dental Ceramics, 2nd ed. 1995.

36- Irwin GR. Analysis of stresses and strains near the end of crack transversing a plate. J Appl Mech 1957;24:361-4.

37- Johnson CA. Fracture statics of multiple flaw distribution. In: Bradt RC, Evans AG, Hasselman DPH, Lange FF, eds. Fracture mechanics of ceramics, vol. 5, Surface flaws, statics, and microcracking. New York, NY: Plenum Press; 1983. p. 365-86.

38- Jung Y-G, Wuttiphan S, Peterson IM, Lawn BR. Damage modes in dental layer structures. J Dent Res 1999; 78:887-97.

39- Kelly JR, Campbell SD, Bowen HK. Fracture-surface analysis of dental ceramics. J Prosthet Dent 1989; 62:536-41.

40- Kelly JR, Giordano R, Pober R , Cima MJ. Fracture surface analysis of dental ceramics: clinically failed restorations. Int J Prosthodont 1990; 3:430-40.

41- Kelly JR. Perspectives on strength. Dent Mater 1995; 11:103-10.

42- Kingery WD, Bowen HK, Uhlmann DR. Introduction to ceramics. 2d ed. New York: Wiley; 1976.

43- Kulawansa DM, Jensen LC, Langford SC, Dickinson JT, Watanabe Y. Scanning tunneling microscope observations in the mirror region of silicate glass fracture surfaces. J Mat Res 1994;9:476-85.

44- Lawn BR, Lee SK, Peterson IM, Wuttiphan S. Model of strength degradation from Hertzian contact damage in tough ceramics. J Am Ceram Soc 1998;81:1509-20.

45- Mackert Jr JR, Butts MB, Fairhurst CW. The effect of the leucite transformation on dental porcelain expansion. Dent Mater 1986; 2:32-

46- Mackert Jr JR, Evans AL. Effect of cooling rate on leucite volume fraction in dental porcelains. J Dent Res 1991; 70:137-9. 
47- Mackert Jr JR, Williams AL. Microcracks in dental porcelain and their behavior during multiple firing. J Dent Res 1996; 75:1484-90.

48- Mandelbrot BB. The Fractal Geometry of Nature. San Francisco: W. H. Freeman \& Co; 1982

49- Mandelbrot BB, Passoja DE, Paulley AJ. Fractal character of metals. Nature 1984;308:721-2.

50- McCabe JF, Carrick TE. A statistical approach to the mechanical testing of dental materials. Dent Mater 1986;2:139-42.

51- Mecholsky Jr. JJ, Freiman SW, Rice RW. Fractographic analysis of ceramics. In: Strauss BM, Cullen WH, eds. Fractography in Failure Analysis, ASTM STP 645. Philadelphia: American Society for Testing and Materials; 1978. p. 363-79.

52- Mecholsky Jr. JJ. Toughening in glass ceramics through microstructural design. In: Bradt RC, Hasselman DPH, Lange FF, eds. Fracture Mechanics of Ceramics. The Pennsylvania State University, University Park, PA. New York: Plenum Press; 1981. p. 165-80.

53- Mecholsky Jr. JJ, Mackin TJ, Passoja DE. Self-similar crack propagation in brittle materials. In: Frechette VC, Varner J, eds. Advances in ceramics. Fractography of glasses and ceramics. Westerville: Am Cer Soc; 1988 . v.22, p. 127-34

54- Mecholsky Jr. JJ, Passoja DE, Feinberg-Ringel KS. Quantitative analysis of brittle fracture surfaces using fractal geometry. J Am Ceram Soc 1989;72:60-5.

55- Mecholsky Jr. JJ, Freiman SW. Relationship between fractal geometry and fractography. J Am Ceram Soc 1991; 74:3136-8.

56- Mecholsky Jr. JJ, Plaia JR. Fractal analysis on fracture surfaces of glass using replication techniques. J Non-Cryst Solids 1992; 146:24955.

57- Mecholsky Jr. JJ. Quantitative fracture surface analysis of glass materials. In: Simmons CJ, El-Bayoumi O, eds. Experimental techniques of glass science. Westerville: Am Cer Soc; 1993. p. 483-520.

58- Mecholsky Jr. JJ. Fractography: determining the sites of fracture initiation. Dent Mater 1995; 11:113-6.

59- Mecholsky Jr. JJ. Fracture mechanics principles. Dent Mater 1995 $11: 111-2$

60- Mecholsky Jr. JJ. Fractography, fracture mechanics, and fractal geometry: An integration. In Varner JR, Frechette VD, Quinn GD, editors. Fractography of glasses and ceramics III. Ceramic Transactions 64; 1996. p. 385-93.

61- Peterson IM, Pajares A, Lawn BR, Thompson VP, Rekow ED. Mechanical characterization of dental ceramics by Hertzian contacts. J Dent Res 1998; 77:589-602.

62- Peterson IM, Wuttiphan S, Lawn BR, Chyung K. Role of microstructure on contact damage and strength degradation of micaceous glass-ceramics. Dent Mater 1998;14:80-9.

63- Piche PW, O’Brien WJ, Groh CL, Boenke KM. Leucite content of selected dental porcelains. J Biomed Mater Res 1994;28:603-9.

64. Rahaman MN. Ceramic processing and sintering. New York: Marcel Dekker, Inc. 1995.

65- Randall PN. Plain strain crack toughness testing of high strength metallic materials. In: Brown Jr. WF, Strawley JE, eds. ASTM STP 410. Philadelphia: Am Soc Test Mater; 1966. p. 88-126.
66- Rice RW. Perspective on fractography. In: Frechette VC, Varner J, eds. Advances in Ceramics, Vol 22: Fractography of Glasses and Ceramics. Westerville: Am Cer Soc; 1988. p. 127-34.

67- Rice RW. Ceramic fracture features, observations, mechanisms, and uses. In: Mecholsky Jr. JJ, Powell Jr. SR, editors. Fractography of ceramic and metal failures, ASTM STP 827. Philadelphia: American Society for Testing and Materials; 1984. p. 5-103.

68- Ritter JE. Critique of test methods for lifetime predictions. Dent Mater 1995; 11:147-51.

69- Ritter JE. Predicting lifetimes of materials and material structures. Dent Mater 1995; 11:142-6.

70- Roulet JF, Söderholm KJ, Longmate J. Effects of treatment and storage conditions on ceramic/composite bond strength. J Dent Res 1995; 74:381-7.

71- Russ JC. Fractal surfaces. New York, NY: Plenum Press. 1994.

72- Scherrer SS, Denry IL , Wiskott HW. Comparison of three fracture toughness testing techniques using a dental glass and a dental ceramic. Dent Mater 1998; 14:246-55.

73- Scherrer SS, Kelly JR, Quinn GD, Xu K. Fracture toughness $\left(\mathrm{K}_{\mathrm{IC}}\right)$ of a dental porcelain determined by fractographic analysis. Dent Mater 1999; 15:342-8.

74- Thompson GA. Influence of relative layer height and testing method on the failure mode and origin in a bilayered dental ceramic composite. Dent Mater 2000;16:235-43.

75- Thompson JY, Anusavice KJ, Naman A, Morris HF. Fracture surface characterization of clinically failed all-ceramics crowns. J Dent Res 1994;73:1824-32.

76- Tsai YL, Mecholsky Jr. JJ. Fractal fracture of single crystal silicon. J Mater Res 1991;6:1248-63.

77- Wakabayashi N, Anusavice KJ. Crack initiation modes in bilayered alumina porcelain disks as a function of core/veneer thickness ratio and supporting substrate stiffness. J Dent Res 2000;79:1398-404.

78- Weibull W. A statistical theory of the strength of materials. Ing Vetensk Akad Proc 1939; 151:1-45.

79- West JK, Mecholsky Jr. JJ, Hench LL. The application of fractal and quantum geometry to brittle fracture. J Non-Cryst Solids 1999; 260:99-108.

80- Wu CC, Freiman SW, Rice RW , Mecholsky Jr. JJ. Microstructural aspects of crack propagation in ceramics. J Mater Sci 1978;13:265970

81- Wuttiphan S, Lawn BR, Padture NP. Crack suppression in stronglybonded homogeneous/heterogeneous laminates: a study on glass/glass ceramic bilayers. J Am Cer Soc 1996; 79:634-40. 
O arquivo disponível sofreu correções conforme ERRATA publicada no Volume 13 Número 2 da revista. 